\title{
The Influence of Psycholinguistic Variables on Articulatory Errors in Naming in Progressive Motor Speech Degeneration.
}

\author{
PLATFORM PRESENTAT5ION ONLY
}

\begin{abstract}
We describe an analysis of speech errors on a naming task in a man with progressive speech degeneration. Early assessment indicated naming impairments with no significant phonological or semantic impairment. To examine naming and the factors that influence speech errors, we selected 210 words varying in lexical and phonetic variables and conducted logistic regression analysis on speech error types. No significant naming errors were found. The only significant predictor of articulation errors was phonemic length and the only error type predicted was phope omissions. Results suggest that the sound omissionss in naming are caused by motor speech impairment unrelated to lexical factors.
\end{abstract}




\section{Introduction}

Progressive speech deterioration occurs either in combination with progressive language/cognitive impairments or as relatively pure speech impairments (e.g., Cohen et al., 1993; Brousolle et al., 1996; Silveri et al., 2003; Ricci et al., 2008), that are not dysarthric nor (par)aphasic conditions.

Naming problems are common in progressive aphasia and can have a variety of causes arising at semantic, lexical, phonological and/or phonetic levels and a range of psycholinguistic variables can impact on access (Ellis \& Young, 1998). Our participant (C.S.) had a progressive speech impairment, but was also reported to have some significant anomia earlier in the progression. However, his 'anomia' may have been due to mis-classification of articulatory errors. To test if C.S. had lexical access impairments, and to test the hypothesis that his articulatory errors in naming were associated with lexical access, we conducted logistic regression analyses on the occurrence of errors in confrontation naming of 210 words varying in frequency, imageability, age of acquisition (AoA), phonemic and syllabic length.

\section{Method}

C.S. was aged 62, right-handed man at the time of testing. He obtained a First Class degree in chemistry from Manchester University, England, and was Head of Chemistry in a well-known British public (i.e. 'private') school for 21 years before early retirement because of increasing speech problems, first noticed in 1992.

Neurological investigation in 1995 included neuropsychological screening, CT scan, EEG, EMG and nerve conduction examinations that were all normal. In November, 2000 slightly brisk reflexes and flexible planter responses were noted. MRI scanning in March, 2001 revealed some mild non localised atrophy considered normal for his age and EEG was normal. MRI in October, 2003 showed significant generalised, bilateral atrophy, more prominent in left frontotemporal area, increased in left frontal dorsomedial regions, suggesting a predominantly fronto-temporal degeneration.

By August, 2002 longitudinal testing had been completed of intelligence, perception, memory, language and action/gesture (details in Table1 in Code et al., 2006). The tests of naming reported here took place in January, 2002.

Extensive testing (see Code et al, 2009) showed intact phonological, grammatical and semantic systems (agrammatic agraphia and sentence processing impairments emerged some months later), and 'naming' impairments noted before this investigation began. But, this anomia is confounded by speech initiation and articulatory errors and some may have been due to unrecognised motor speech problems before this investigation. LT, ST memory and perceptual processing and IQ were unimpaired. Executive impairment and impulsivity were noted with significant limb, buccofacial and ocular motor apraxia.

C.S died in December, 2007, and post mortem confirmed Pick’s disease. MRI scans and autopsy information can be seen in Code et al. (2009).

We selected 210 nouns varying in frequency, imeagability, age of acquisition (AoA), phonemic and syllabic length. Testing was audio-recorded. 
Speech was analysed by two experienced speech scientists with the aid of PRAAT analysis software (version 4.0.26). All phone omissions, additions or substitutions ${ }^{1}$ and initiation delays were recorded.

\section{Results}

Table 1 shows a summary of initial testing of speech by February 2002. Screening on the Motor Speech Examination (Wertz et al., 1984) and the Dabul Apraxia Test (Dabul, 2000) revealed a range of impairments.

C.S. produced just 8 naming errors on the 210 pictures with 78 articulatory errors consisting of 29 additions, 26 substitutions and 16 omissions, with 30 initiation delays. Table 2 shows the numbers of each kind of error type. This firstly confirmed that his 'naming' impairment probably was due to articulatory rather than lexical access difficulties and we concluded that C.S. did not have significant lexical access impairment.

Logistic regression examined if any of the dependent lexical variables predicted the occurrence of any form of speech errors, the independent variables. The only variable to predict errors was phonemic length, and the only error type predicted was phone omissions $(\beta=.642$; Wald=7.257; $p=.007$ ), with none of the other error types predicted by the lexical variables. Omissions occurred significantly more often in C.S.'s naming with phonemically longer words.

\section{Discussion}

C.S. produced more substitutions and additions than omissions, but the substitutions and additions were not predicted by the regression analysis. Why does word length predict omissions, but not substitutions and additions? Studies have identified additions (e.g., Rosenbek et al,) and substitutions (e.g., Itoh \& Sasanuma, 1984) as common in apraxia of speech. Why omissions occur and are predicted by the regression analysis is perhaps relatively clear: it is easier for a compromised speech mechanism to omit a phone in a word, especially a longer word, than to struggle to produce the whole word, whereas inserting an additional phone should be harder for an apraxic speaker. However, phone additions too are features of apraxic speech. We interpret these additions as motor speech errors: C.S. tends to add sounds to words in a range of naming, reading and repetition tasks, and schwa-like intrusions account for many of his additions and many are concerned with splitting up clusters, which is independent of word length. Rosenbek et al. (1984) show that such intrusions should not be considered 'phonemes', but transitions that are 'intervals of continuous articulatory change' (p.17), which coincides with our view of C.S.'s intrusive schwas. Schwa-like intrusions for C.S. are compensatory aiding his production of ongoing speech. Classification of errors into substitutions are problematic (e.g., Itoh \& Sasanuma, 1984) as they are often interpreted as phonological rather than phonetic errors. For C.S. substitutions often occur where he didn't properly align certain gestures (e.g. $/ \mathrm{m} /$ to [b] where the nasal gesture was uncoupled, and in voicing errors, and these too can be independent of length, a probable reason that substitutions were not predicted by phonemic length.

\footnotetext{
${ }^{1}$ The term 'substitution' here covers any incorrect realization, not solely phonemic substitutions; see discussion below.
} 
Listeners make errors when they perceive speech, and many studies of AOS have employed perceptual methods where investigators' own perceptual systems make decisions on the speech they hear and many have not been well controlled for what is known as phonemic false evaluation (PFE) (Buckingham \& Yule, 1987). Perceivers tend to classify phones in terms of categorical perception (MacNeilage, 1982) - the strong tendency to classify a phone as belonging to one or another phonetic category and to ignore features that do not contribute to categorical perception. Trained phonetic listeners too are subject to categorical perception. Buckingham and Yule (1987) reviewed the implications of PFE and suggest that it is an automatic property of the cognitive system, and listeners cannot help perceiving categorically. This can lead listeners to falsely evaluate an intended phoneme, especially where a failure of motor control produces a switch in an acoustic cue. PFE may account for a significant proportion of the phonemic substitutions reported in the literature.

The category of substitution is not well motivated because using it when errors are to do with motor planning and/or execution conflates the source and effect distinction (see Ball and Müller 2002): classifying an error as a substitution (i.e. as phonemic) is only saying that it 'sounds' like the sound is a separate phoneme to the target. It is usually not possible to state that the speaker deliberately chose to use a sound from another phoneme. Even when we hear what appears to be a substitution, the speaker may have produced a covert contrast. Thus, the speaker may maintain separate gestures for the two sounds, but to the listener the sounds appear merged. For example, both English /s/ realized as a dental sibilant and as a lateral frictative would be classed as distortions, even though the first is close to the target whereas the second is not even an English sound.

We found no evidence for impaired phonology in extensive testing and conclude that C.S.'s speech errors on a naming task varying in lexical and phonetic variables suggest that errors arise as a result of compromise to speech programming/planning.

\section{References}

Broussolle, E., Bakchine, S., Tommasi, M., Laurent, B., Bazin, B., Cinotti, L. Cohen, L. \& Chazot, G. (1996) Slowly progressive anarthria with late anterior opercular syndrome: a variant form of frontal cortical atrophy syndromes. Journal of the Neurological Sciences 144, 44-58

Buckingham, H. \& Yule, G (1987) Phonemic false evaluation: theoretical and clinical aspects. Clinical Linguistics and Phonetics, 1, 113-125.

Code, C., Tree, J. \& Dawe, K. (2009) Opportunities to say 'yes': rare speech automatisms in a case of progressive nonfluent aphasia and apraxia. Neurocase, 15 , 445-458

Code, C., Müller, N., Tree, J.T. \& Ball, M.J. (2006) Syntactic impairments can emerge later: progressive agrammatic agraphia and syntactic comprehension impairment. Aphasiology, 20, 1035-1058.

Cohen, L., Benoit, N., Van Eeckhout, P., Ducarne, B, and Brunet, P. (1993) Pure progressive aphemia. J, Neurol. Neurosurg. Psychiatry, 56: 923-924.

Croot, K., Patterson, K. \& Hodges, J.R. (1998) Single word production in nonfluent progressive aphasia. Brain \& Language, 61, 226-273.

Dabul, B. (2000). Apraxia battery for adults (2nd ed) Port Coquitlam, BC: PsychTest, M. D. Angus \& Associates. 
Duffy, J.R. (2006) Apraxia of speech in degenerative disease. Aphasiology, 20, 511-527. Ellis, A.W. \& Young, A.W. (1998) Human Cognitive Neuropsychology. $2^{\text {nd }}$ Edition. Psychology Press: Hove, East Sussex.

Hart, R.P., Beach, W.A. \& Taylor, J.R. (1997) A case of progressive apraxia of speech and non-fluent aphasia. Aphasiology, 11, 73-82.

Kay, J., Lesser, R., \& Coltheart, M. (1992). PALPA: Psycholinguistic assessment of language processing in aphasia. Hove, UK: Lawrence Erlbaum.

MacNeilage, P.F. (1982) Speech production mechanisms in aphasia. In S. Grillner, B. Lindblom, J. Lubker and A. Perrson, (eds), Speech Motor Control, Pergamon Press: Oxford.

Ricci, M., Magarelli, M., Todino, V., Bianchini , A., Calandriello, E., Tramutoli , R. (2008) Progressive apraxia of speech presenting as isolated disorder of speech articulation and prosody: A case report. Neurocase, 14, 162 - 168

Rosenbek, J.C., Kent, R.D. \& LaPointe, L.L. (1984) Apraxia of speech: an overview and some perspectives. In: J.C. Rosenbek, M.R. McNeil \& A.E. Aronson (eds.), Apraxia of Speech: Physiology, Acoustics, Linguistics, Management. San Diego: College-Hill Press. (pp.1-72).

Silveri, M.C., Cappa, A. \& Salvigni, B.L. (2003) Speech and language in primary progressive anarthria. Neurocase, 9, 213-220.

Tyrrell, P,J,, Kartsounis, L.D., Frackowiak, R.S.J,, Findley, L,J, and Rossor, M.N. (1991) Progressive loss of speech output and orofacial dyspraxia associated with frontal lobe hypometabolism, J. Neurol. Neurosurg. Psychiatry, 54: 351-357.

Wertz, R.T., LaPointe, L.L. \& Rosenbek, J.C. (1984) Apraxia of Speech: the Disorder and Its Management. New York: Grune \& Stratton. 
Table 1. Summary of results of initial investigations of speech production.

\begin{tabular}{|c|c|}
\hline $\begin{array}{l}\text { Motor Speech } \\
\text { Examination (Wertz et al, } \\
\text { 1984) }\end{array}$ & $\begin{array}{l}\text { No significant motor or sensory loss; some possible spastic } \\
\text { dysarthria. Prosodic disturbance. No dysphagia. Problems } \\
\text { initiating laryngeal \& oral movement }\end{array}$ \\
\hline $\begin{array}{l}\text { Boston Rating Scale } \\
\text { Profile of Speech } \\
\text { Characteristics } \\
\text { (each rated 1-7) }\end{array}$ & $\begin{array}{l}\text { Melodic Line: } 4 \text { (short phrases) } \\
\text { Phrase length: } 4 \text { (4-5 words) } \\
\text { Artic Agility: 3-4 (could be normal in familiar } \\
\text { words/phrases } \\
\text { Grammar Form: 4-5 (ltd but correct) } \\
\text { Paraphasia: } 7 \text { (absent) } \\
\text { Word Finding: } 5 \text { (proportional to fluency) } \\
\end{array}$ \\
\hline $\begin{array}{l}\text { Dabul Apraxia Test } \\
\text { Diadochokinetic (ddk) } \\
\text { rate } \\
\text { Alternating ddk rate }\end{array}$ & $\begin{array}{l}\text { 2/3 repetitions; } \\
\text { some voicing of voiceless stops; } \\
\text { some vowel substitutions. } \\
\text { Little or no groping/searching. } \\
\text { increasing initiation problems \& pausing with progress } \\
\text { through automatic counting series. Increasing initiation } \\
\text { problems }\end{array}$ \\
\hline $\begin{array}{l}\text { Dabul naming \& } \\
\text { repeating } 3 \text { syllable words }\end{array}$ & $\begin{array}{l}\text { Errors increased with length; intrusive schwa, between } \\
\text { clusters; } \\
\text { devoicing +voice \& voicing -voiced fricatives/stops; } \\
\text { some vowel distortions; anticipation of phones; increasing } \\
\text { errors on repetition. Some problems with control of voicing } \\
\text { and co-ordination of laryngeal with oral articulation }\end{array}$ \\
\hline $\begin{array}{l}\text { Grandfather Passage } \\
\text { Reading Aloud }\end{array}$ & $\begin{array}{l}\text { Significant initiation problems; pausing between } \\
\text { words/phrases; Time } 180 \text { secs. (normal = } 46 \text { secs) }\end{array}$ \\
\hline Picture Description & $\begin{array}{l}30 \text { words (including } 4 \text { occurrences of the automatism yes) in } \\
51 \text { secs. }\end{array}$ \\
\hline Phonemic Processing & $\begin{array}{l}\text { PALPA 1-3 Auditory Discrimination, No Errors } \\
\text { Auditory discrimination word/ nonword } \\
\text { No Delay: 32/32 } \\
\text { Delay (5 Sec.): 30/32 } \\
\text { Filled Delay: 32/32 }\end{array}$ \\
\hline $\begin{array}{l}\text { Written word } \\
\text { phonological processing }\end{array}$ & $\begin{array}{l}\text { PALPA } 15 \text { Rhyme Judgement, 55/60 correct } \\
\text { Test } 1 \& 2 \text { Rhyme Judgement, No Errors } \\
\text { PALPA } 28 \text { Homophone judgement, 59/60 correct } \\
\text { Pseudohomophone judgement, } 49 / 50 \text { correct } \\
\text { Regular words, } 49 / 50 \text { correct } \\
\text { Irregular words, 50/50 correct }\end{array}$ \\
\hline
\end{tabular}

Key: PALPA=Psycholinguistic Assessment of Language Processing in Aphasia (Kay et al., 1992) 
Table 2. Speech error types produced.

\begin{tabular}{llllll}
\hline & Errors & Additions & Substitutions & Omissions & Delays \\
& & & & & \\
\hline TOTALS & 78 & 29 & 26 & 16 & 30 \\
\hline
\end{tabular}

